\title{
PERANCANGAN SISTEM PENENTUAN OBJEK WISATA PANTAI TERBAIK DI BALI MENGGUNAKAN METODE FUZZY AHP (F- AHP)
}

\author{
Sutrisno \\ Program Studi Teknik Informatika, Fakultas Teknik, Matematika dan IPA \\ Universitas Indraprasta PGRI \\ Email: sutrisno3831@gmail.com \\ Adhi Susano \\ Program Studi Teknik Informatika, Fakultas Teknik, Matematika dan IPA \\ Universitas Indraprasta PGRI \\ Email: adhi.susano@gmail.com \\ Agus Darmawan \\ Program Studi Teknik Informatika, Fakultas Teknik, Matematika dan IPA \\ Universitas Indraprasta PGRI \\ Email: agay.unindra08@gmail.com
}

\begin{abstract}
ABSTRAK
Penelitian ini bertujuan untuk membuat sistem penentu pemberian penetapan Objek wisata terbaik. Sistem penentu pemberian penetapan Objek wisata terbaik berdasar kriteria internal dan eksternal Dari metode yan gpernah dilakukan masih didapatkan ketidakpastian penilaian yang terlalu subjektif. Oleh karena itu, dibutuhkan metode penyeleksian penentuan Objek wisata agar mendapatkan hasil yang lebih dapat dipertanggungjawabkan. Perancangan sistem pendukung keputusan ini menggunakan metode fuzzy analytic hierarchy process dalam memberikan pertimbangan kepada masyarakat untuk menentukan tujuan objek wisata. Metode Fuzzy AHP (F-AHP) merupakan penggabungan metode AHP dan pendekatan fuzzy. Metode F-AHP menutupi kekurangan pada AHP dalam menangani ketidakpastian penilaian yang terlalu subjektif untuk data kualitatif. Metode F-AHP menggunakan penilaian dalam interval sehingga data yang kualitatif dapat memberikan penilaian yang lebih obyektif. Inti dari F-AHP terletak pada perbandingan berpasangan yang digambarkan dengan skala rasio yang berhubungan dengan skala fuzzy. Berdasarkan hasil penelitian dapat diambil kesimpulan, hasil dari sistem berupa rancangan aplikasi dari system keputusan peranking kandidat Objek wisata pantai terbaik perhitungan nilai prioritas dan skala fuzzy AHP.
\end{abstract}

Kata kunci: objek wisata, internal, eksternal, metode fuzzy AHP (F-AHP).

\begin{abstract}
This study aims to create a determinant system of awarding the best tourist object. Determining system of determination of the best tourist object based on internal and external criteria From the method yan gpernah done still get uncertainty assessment which is too subjective. Therefore, it is necessary to select the method of selecting tourism object to get more accountable result. The design of this decision support system using fuzzy analytic hierarchy process method in giving consideration to the community to determine the destination of the tourist attraction. Fuzzy AHP method $(F-A H P)$ is a combination of AHP and fuzzy approaches. The F-AHP method masks a deficiency in AHP in dealing with the overly subjective assessment uncertainty for qualitative data. The F-AHP method uses assessment in intervals so that qualitative data can provide more objective assessments. The core of the F-AHP lies in pairwise comparisons that are illustrated by the scale of the scale associated with the fuzzy scale. Based on the results of the research can be concluded, the results of the system in the form of application design of the decision system peranking candidate Coastal attractions best calculation of priority value and fuzzy scale AHP.
\end{abstract}

Keywords: tourist attraction, internal, external, fuzzy AHP method (F-AHP). 


\section{PENDAHULUAN}

Kegiatan kepariwisataan di Indonesia merupakan salah satu sektor andalan yang mampu menggalakkan kegiatan ekonomi nasional , baik sebagai penghasil devisa, penyedia lapangan kerja, maupun sebagai pendorong peningkatan pendapatan masyarakat.

Secara empiris pariwisata telah menunjukkan pertumbuhan yang terus meningkat ditandai dengan peningkatan frekuensi orang yang melakukan perjalanan. Kegiatan pariwisata banyak menciptakan manfaat antara lain penyebaran pembangunan, pemasukan devisa, penerimaan daerah melalui pungutan pajak, penyerapan tenaga kerja dan menciptakan peluang usaha.

Permasalahan yang sering muncul masih banyak orang yang berwisata tapi malah menimbulkan beban pikiran baru. Berwisata juga merupakan kebutuhan jasmani yang penting tanpa sadari. Karena dengan berwisata dapat menghilangkan penat akibat aktivitas selama seharian. Pemilihan objek wisata yang tepat juga berpengaruh dalam hal ini. Oleh karena itu menyadari betapa pentingnya memilih objek wisata yang tepat, maka dibutuhkan sebuah sistem dalam bidang kepariwisataan. sistem diharapkan dapat digunakan untuk mendapatkan informasi dan pengambilan keputusan pemilihan objek wisata secara efektif dan mampu membantu masyarakat untuk menetukan lokasi objek wisata yang akan ditujunya.

Permasalahan di atas, dapat diselesaikan dengan membangun sebuah Sistem Pendukung Keputusan (SPK) yang dapat membantu masyarakat dalam melakukan penilaian dan penyeleksian penentuan objek wisata terbaik. SPK merupakan suatu model yang dibangun untuk menyelesaikan permasalahan yang terstruktur.

Sistem yang dibangun dengan menerapkan penggabungan metode AHP dengan pendekatan Fuzzy yang disebut Fuzzy AHP. AHP adalah salah satu metode dari Multi Criteria Decision Making (MCDM) yang dikembangkan oleh Prof. Thomas Lorie Saaty dari Wharton Business School di awal tahun 1970 [1]. Namun, AHP mengalami kesulitan dalam menangani penilaian ketidakpastian dan yang bersifat subjektif. Oleh karena itu, salah satu varian AHP yaitu Fuzzy AHP digunakan untuk mengatasi ketidakmampuan AHP dalam menangani variabel linguistik [3]. Dalam prosedur Fuzzy AHP, cara pendekatan yang dilakukan adalah dengan melakukan fuzzifikasi pada skala AHP sehingga diperoleh skala baru yang disebut skala fuzzy AHP [5].

Pengertian objek dan daya tarik wisata menurut undang-undang Nomor 9 Tahun 1990, yaitu Objek dan daya tarik wisata terdiri atas (1) Objek dan daya tarik wisata ciptaan Tuhan Yang Maha Esa, yang berwujud keadaan alam, serta flora dan fauna, (2) Objek dan daya tarik wisata hasil karya manusia yang berwujud museum, peninggalan purbakala, peninggalan sejarah, seni budaya, wisata agro, wisata tirta, wisata buru, wisata petualangan alam, taman rekreasi, dan tempat hiburan.

Bali merupakan salah satu provinsi di Indonesia yang wilayahnya terdiri atas satu pulau, yaitu Pulau Bali dan beberapa pulau-pulau kecil di sekitarnya. Di antara pulau kecil tersebut, pulau yang paling besar adalah Nusa Penida yang berada di tenggara Pulau Bali. Luas seluruh wilayah Provinsi Bali adalah $5633 \mathrm{~km}^{2}$. Bali memiliki objek wisata yang sangat beragam, baik wisata alam, wisata budaya, dan wisata bahari. Di Bali terdapat sekitar 54 lokasi objek wisata yang tersebar di delapan kabupatennya.

Pada hakekatnya AHP merupakan suatu model pengambil keputusan yang komprehensif dengan memperhitungkan hal- hal yang bersifat kualitatif dan kuantitatif. AHP juga memungkinkan ke struktur suatu sistem dan lingkungan kedalam komponen saling berinteraksi dan kemudian menyatukan mereka dengan mengukur dan mengatur dampak dari komponen kesalahan sistem [4].

Fuzzy Analytic Hierarchy Process (F-AHP) dapat dilihat sebagai metode analitik yang dikembangkan dari metode AHP. F-AHP merupakan penggabungan dari metode AHP dengan logika matematika Fuzzy. Perbedaannya dengan AHP adalah implementasi bobot perbandingan berpasangan di dalam matriks perbandingan, yakni diwakili oleh tiga variabel $(\mathrm{a}, \mathrm{b}, \mathrm{c})$ atau $(\mathrm{l}, \mathrm{m}, \mathrm{u})$ yang disebut Triangular Fuzzy Number (TFN). Hal ini berarti bobot yang ditemukan bukan satu melainkan tiga, sesuai dengan fungsi keanggotaan segitiga yang meliputi tiga bobot berurutan [2].

\section{METODOLOGI PENELITIAN}

Metode Penelitian bisa meliputi jenis dan suber data, metode pengumpulan data, perancangan yang dipakai untuk menyelesaikan masalah dalam bahasan ini penulis menguraikan langkah - langkah dalam metode. 


\subsection{Jenis dan Sumber Data}

Data primer merupakan data yang diambil secara langsung dari sumbernya, yaitu objek penelitian. Dalam penelitian ini, objek penelitian yang dimaksud berupa materi-materi dan syarat - syarat dalam penentuan objek wisata terbaik di Bali.

Data sekunder merupakan data yang diambil secara tidak langsung dari sumbernya. Dalam laporan tugas akhir ini data sekunder diperoleh dari buku-buku kepustakaan, jurnal-jurnal ilmiah, paper, tesis, dan mencari informasi dari internet, yang dijadikan sebagai landasan teori serta pelengkap data primer.

\subsection{Metode Pengumpulan Data}

Dalam menyusun tugas akhir ini untuk mendapatkan kebenaran data, penulis menggunakan berbagaimetode pengumpulan data untuk melakukan penelitian ini. Adapun metode-metode tersebut adalah :

a. Metode Kuisioner

Penulis melakukan pemberian kuisioner untuk memperoleh data-data yang digunakan untuk pembuatan system, meliputi kategori dan penentuan nilai. pemberian kuisioner dilakukan di Bali, dengan sasaran pengujung wistawan objek wisata.

b. Metode Studi Pustaka

Pengumpulan data dilakukan dengan cara melakukan kajian pustaka mengenai teori - teori yang terkait berupa buku, artikel, jurnal, dan artikel dalam web. Teori tersebut diantaranya mengenai perancangan dan dasar - dasar pembuatan Sistem Pendukung Keputusan dengan metode AHP , Fuzzy, dan Fuzzy Analytical Hierarchy Process (F-AHP).

\section{HASIL DAN PEMBAHASAN}

Pembahasan terhadap hasil penelitian dan perancangan yang diperoleh disajikan dalam bentuk uraian teoritik, baik secara kualitatif maupun kuantitatif. Hasil perancangan ditampilkan dalam berupa Flowchart ataupun Pseudocode.

\subsection{Hasil Pembobotan Kriteria Dan Sub Kriteria}

Dalam melakukan penelitian, peneliti mengumpulkan data dari beberapa pengujung objek wisata bali. sehingga di dapat lah pembobotan terhadap kriteria dan sub kriteria pendukung Penentuan objek wisata terbaik. Hasil dari pembobotan tersebut dapat dilihat pada Tabel I.

Tabel 1. Hasil pembobotan kriteia dan sub kriteria

\begin{tabular}{|c|c|c|c|c|}
\hline \multirow{2}{*}{$\begin{array}{c}\text { Kriteria / Sub } \\
\text { Kriteria }\end{array}$} & \multicolumn{3}{|c|}{ Bobot Fuzzy- AHP } & \multirow[b]{2}{*}{$\boldsymbol{A H P}$} \\
\hline & $L$ & $M$ & $\boldsymbol{U}$ & \\
\hline L1 & 0.18669595 & 0.273115 & 0.370232 & 2.318429482 \\
\hline $\mathrm{L} 2$ & 0.18669595 & 0.091038 & 0.080778 & 17.54313434 \\
\hline L3 & 0.06223198 & 0.054623 & 0.05289 & 17.46917088 \\
\hline L4 & 0.03733919 & 0.039016 & 0.037931 & 20.24015324 \\
\hline L5 & 0.02667085 & 0.030346 & 0.041137 & 9.143947185 \\
\hline L6 & 0.18669595 & 0.273115 & 0.160808 & 4.645054559 \\
\hline L7 & 0.18669595 & 0.091038 & 0.074046 & 10.12007662 \\
\hline L8 & 0.06223198 & 0.054623 & 0.05289 & 13.58713291 \\
\hline L9 & 0.03807133 & 0.062738 & 0.042027 & 6.578675379 \\
\hline L10 & 0.02667085 & 0.030346 & 0.08726 & 2.318429482 \\
\hline
\end{tabular}

Tabel 1 menunjukkan hasil pembobotan dari keseluruhan kriteria dan sub kriteria. Bobot fuzzy pada sub kriteria diperoleh dari hasil perkalian antara bobot fuzzy kriteria dengan bobot fuzzy lokal sub kriteria. Sedangkan nilai AHP adalah hasil proses defuzzifikasi dari masing-masing kriteria/sub kriteria. 


\subsection{Algoritma Penyelesaian Masalah Dengan Flowchart}

Perancangan program akan menjelaskan tentang bagaimana program aplikasi berjalan. Perancangan prosedural digambarkan dalam bentuk flowchart atau diagram alir dengan metode Fuzzy-AHP akan memudahkan untuk mengimplementasikan sistem ke dalam bahasa pemograman, karena akan menjelaskan bagaimana cara sistem dari awal hingga akhir.

Tujuan dari pembangunan sistem pengambil keputusan ini yaitu dapat membantu dalam menyelesaikan masalah dalam menentukan prioritas pembagian. Penulis di sini membuat struktur program kemudian Flowchart berikut penjelasannya yaitu dibawah ini:

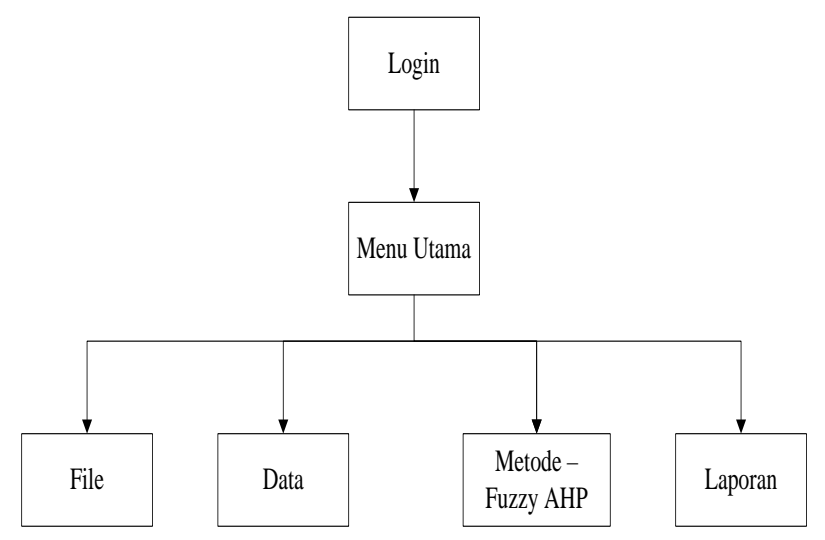

\section{Gambar 1. Struktur Program}

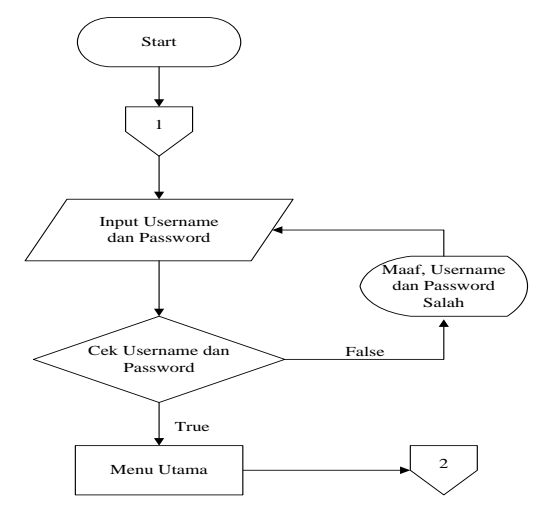

Gambar 2. Flowchart Login

Gambar 2 menunjukkan pseudicode pada halaman Login, admin harus memasukkan username beserta password untuk bisa masuk ke menu utama. Jika login gagal maka akan muncul pesan kesalahan.

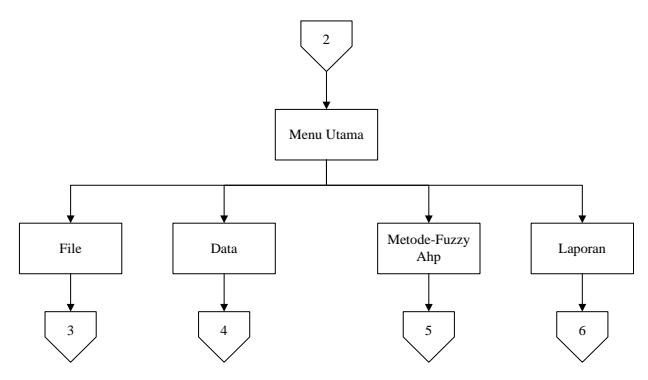

Gambar 3. Flowchart Menu Utama

Pada tampilan menu utama yang ditunjukkan dengan nomor 2 (dua) terdapat beberapa sub menu pilihan yang antara lain "File", "Data", "Metode-fuzzy-Ahp", dan "Laporan". Jika admin memilih menu "File" maka akan ditampilkan menu nomor 3 (tiga). Jika admin memilih menu "Data" maka akan ditampilkan menu nomor 4 (empat). Jika admin memilih menu "Metode-fuzzy-Ahp" maka akan 
ditampilkan menu nomor 5 (lima). Jika admin memilih menu "Hasil" maka akan ditampilkan menu nomor 6 (enam).

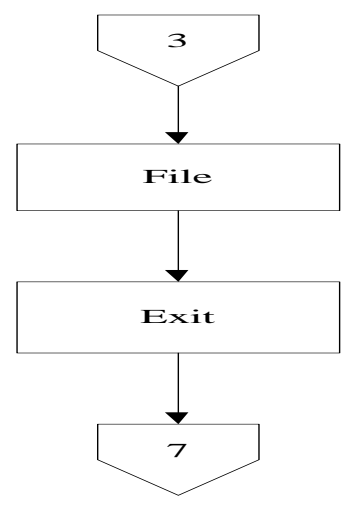

\section{Gambar 4. Flowchart File}

Setelah admin memilih menu "File" yang ditunjukkan dengan nomor 3 (tiga) maka program akan menampilkan menu yang ditunjukkan dengan nomor.

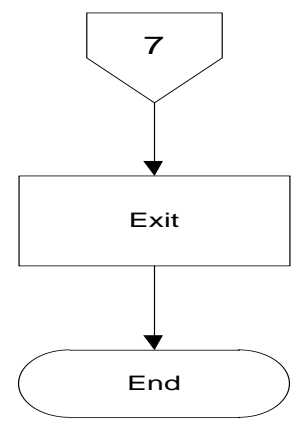

\section{Gambar 5. Flowchart Exit}

Setelah semua proses telah selesai dilakukan maka proses yang terakhir yaitu Exit pada alur nomor 7 (tujuh) yang berfungsi untuk menutup program.

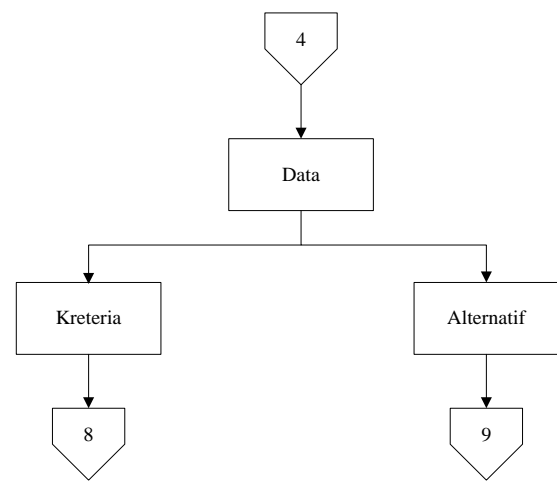

\section{Gambar 6. Flowchart Manage}

Pada gambar 7, setelah admin memilih menu ““، yang ditunjukkan dengan nomor 8 (delapan) maka program akan menampilkan menu “"“ yang berisi tentang pengolahan data Alternatif pada SPK ini. Pada menu ini, jika admin memilih aksi hapus, penghapusan data langsung menghapus data yang ada dalam database Kreteri. Jika admin memilih aksi simpan, admin harus memasukkan data Kreteria, lalu di simpan. Jika data lengkap maka proses simpan berhasil dan menampilkan pesan "Proses Simpan Berhasil". Jika data tidak lengkap maka proses simpan gagal dan menampilkan pesan "Gagal, Data Tidak Lengkap". 
Untuk perubahan data yang sudah ada, data pada database akan ditampilkan lalu dilakukan perubahan data oleh admin. Jika perubahan data yang dimasukkan lengkap maka proses simpan berhasil dan menampilkan pesan "Proses Simpan Berhasil", jika data perubahan tidak lengkap proses simpan gagal dan menampilkan pesan "Gagal, Data Tidak Lengkap". Setelah semua proses selesai maka akan tetap kembali ke menu nomor 4 (empat).

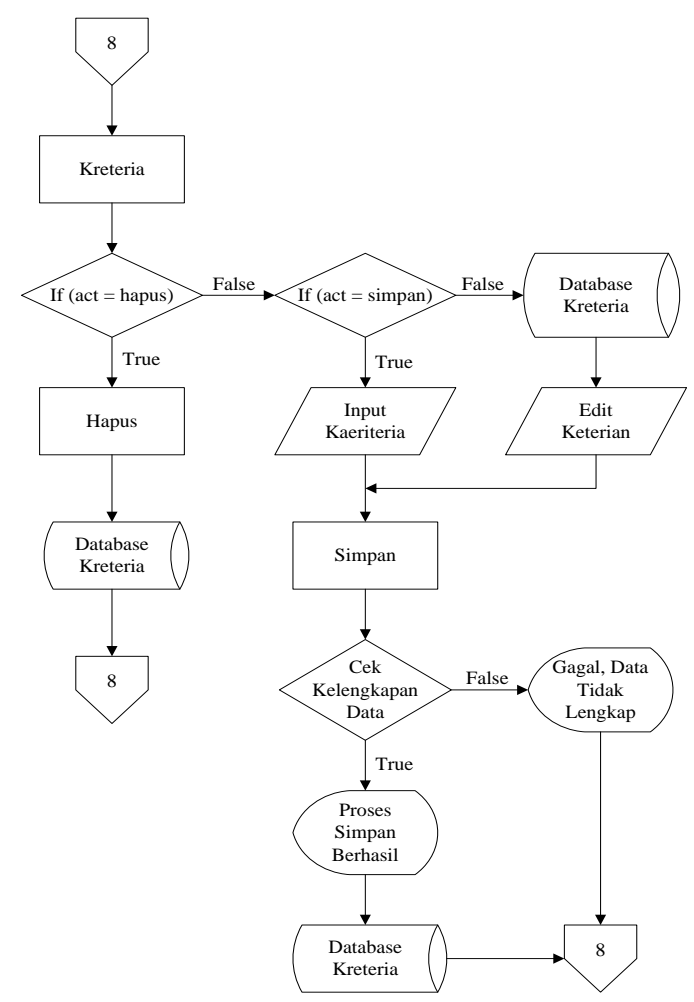

Gambar 7. Flowchart Daftar Kriteria

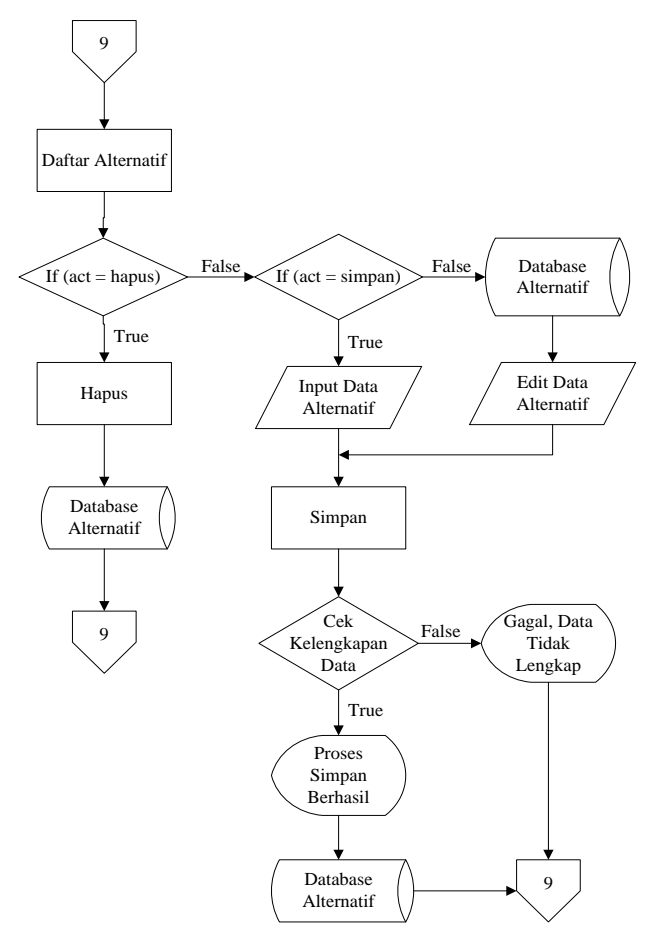

Gambar 8. Flowchart Daftar Alternatif 
Setelah admin memilih menu "Alternatif “ yang ditunjukkan dengan nomor 9 (sembilan) maka program akan menampilkan menu "Alternatif " yang berisi tentang pengolahan data kriteria pada SPK ini. Pada menu ini, jika admin memilih aksi hapus, penghapusan data langsung menghapus data yang ada dalam database Alternatif. Jika admin memilih aksi simpan, admin harus memasukkan data kriteria, lalu di simpan. Jika data lengkap maka proses simpan berhasil dan menampilkan pesan "Proses Simpan Berhasil". Jika data tidak lengkap maka proses simpan gagal dan menampilkan pesan "Gagal, Data Tidak Lengkap". Untuk perubahan data yang sudah ada, data pada database akan ditampilkan lalu dilakukan perubahan data oleh admin. Jika perubahan data yang dimasukkan lengkap maka proses simpan berhasil dan menampilkan pesan "Proses Simpan Berhasil", jika data perubahan tidak lengkap proses simpan gagal dan menampilkan pesan "Gagal, Data Tidak Lengkap". Setelah semua proses selesai maka akan tetap kembali ke menu nomor 4 (empat).

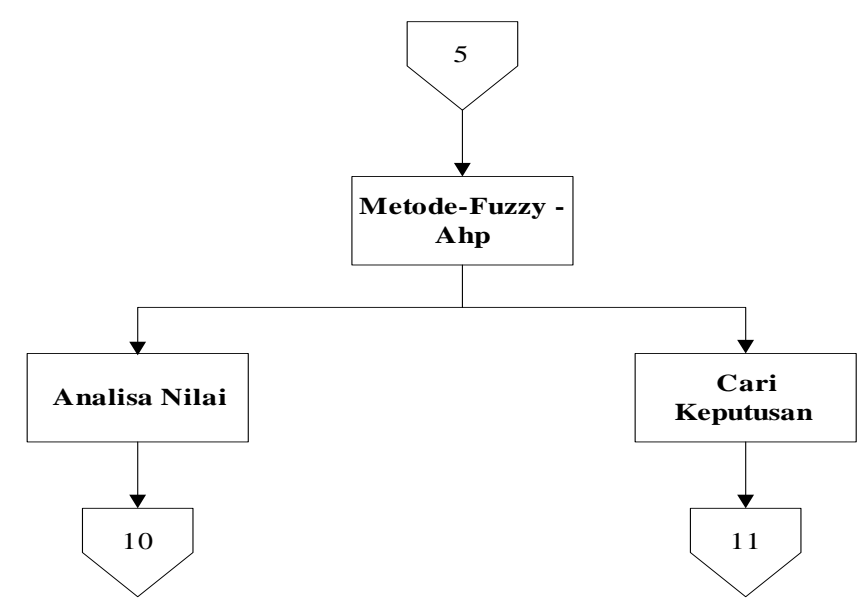

Gambar 9. Flowchart Metode-Fuzzy-AHP

Setelah memilih menu "Metode-Ahp" yang ditunjukkan dengan nomor 5 (lima) maka program akan menampilakan menu "Analisa Nilai dan Cari Keputusan" yang berisi tentang nilai kriteria dan cara mencari keputusan. Setelah semua proses selesai maka akan diteruskan kembali ke alur nomor 2 (dua).

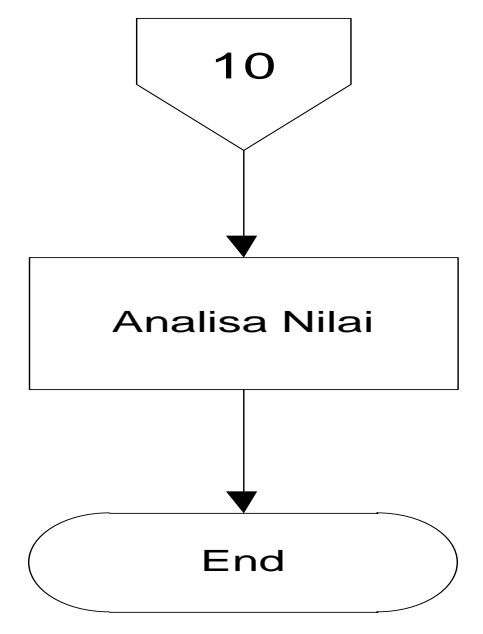

Gambar 10. Flowchart Analisa Nilai 


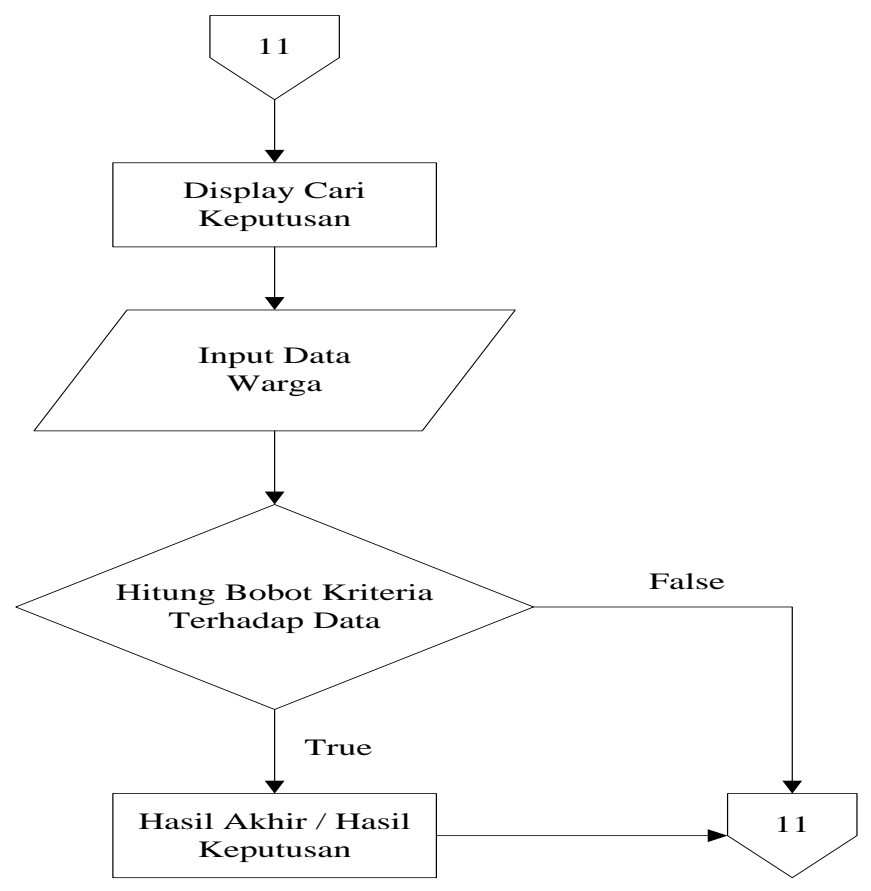

Gambar 11. Flowchart Cari Keputusan

Setelah admin memilih menu "Cari Keputusan" yang ditunjukkan dengan nomor 11 (sebelas) maka program akan menampilkan menu "Cari Keputusan" yang berisi tentang pengolahan data kriteria dan data Kreteria. Pada menu ini admin melakukan perhitungan bobot kriteria terhadap data Warga dengan metode-fuzzy AHP.

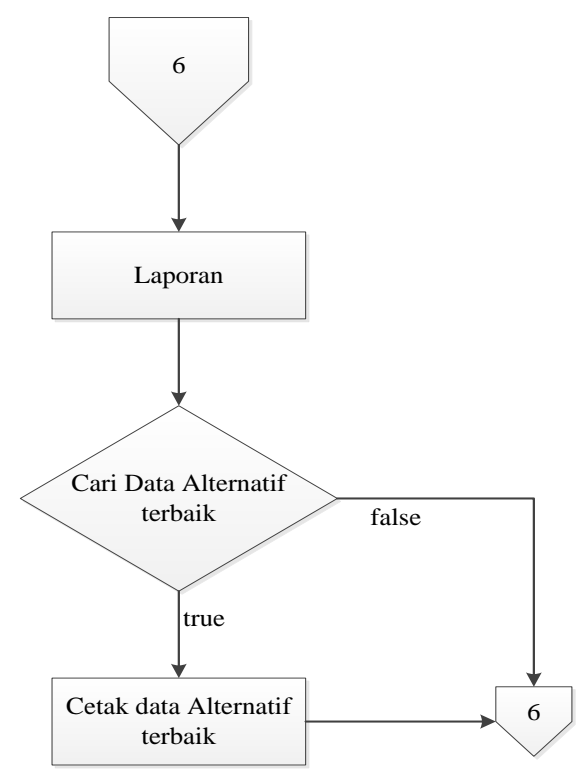

Gambar 12. Flowchart Laporan

Setelah admin memilih menu "Laporan" yang ditunjukkan dengan nomor 6 (enam) maka program akan menampilkan daftar calon penerima. Setelah itu data dapat dicari dan dicetak.

\subsection{Pembahasan Algoritma}

Algoritma adalah urutan dari baris langkah-langkah logis atau instruksi guna menyelesaikan suatu masalah. Sedangkan kegunaan algoritma adalah untuk membantu seseorang dalam menyelesaikan suatu masalah berdasarkan pada pola pikirnya masing-masing. Kriteria algoritma yang baik adalah mempunyai output efektif, jumlah langkah berhingga, terstruktur dan punya akhir. Salah satu cara penyajian dengan 
algoritma yaitu dalam bentuk flowchart. Flowchart adalah gambaran dalam bentuk diagram aliran dari algoritma dalam suatu program yang menyatakan arah alur program dalam menyelesaikan suatu masalah. Adapun algoritma sistem penentu adalah:

\subsubsection{Login}

Pada halaman login ini admin diharuskan mengisi Username dan Password yang sesuai dengan data dalam database agar dapat masuk ke menu utama. Halaman ini berfungsi sebagai fasilitas keamanan atas data penting yang ada pada menu utama, sehingga hanya admin saja yang bisa mengelola data tersebut.

\subsubsection{Menu Utama}

Pada menu utama ini terdapat 4 menu pilihan bagi admin dalam mengolah data sistem yang masingmasing memiliki proses (fungsi) tersendiri. Data keluarannya (output) berupa informasi yang meliputi menu "File" yang berisi tampilan exit, menu "Data" yang berisi form dan daftar karyawan, menu "Metode-fuzzy-AHP" yang berisi cara mencari keputusan sehingga menghasilkan suatu hasil akhir/hasil keputusan, menu "Laporan" yang berisi daftar Perengkingan Alternatif/ pemberian bobot yang dapat dicetak.

\subsection{Rancangan Layar}

Perancangan Layar dibutuhkan untuk mempresentasikan (mewakili) tampilan layar dari keadaan yang sesungguhnya terjadi pada Perancangan Sistem Penentuan objek wisata terbaik dengan Metode fuzzy-AHP. Penulis merancang tampilan sedemikian rupa sehingga mudah digunakan oleh user. Pada sub bab ini akan disajikan rancangan layar dari Perancangan Sistem Penentuan objek wisata terbaik dengan metode fuzzy-AHP, rancangan layar tersebut diperlihatkan pada gambar 13 dan gambar 14.

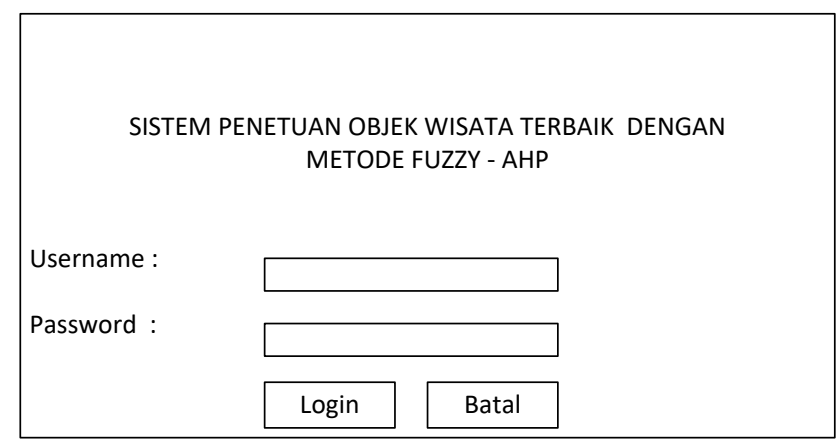

Gambar 13. Rancangan Layar Login

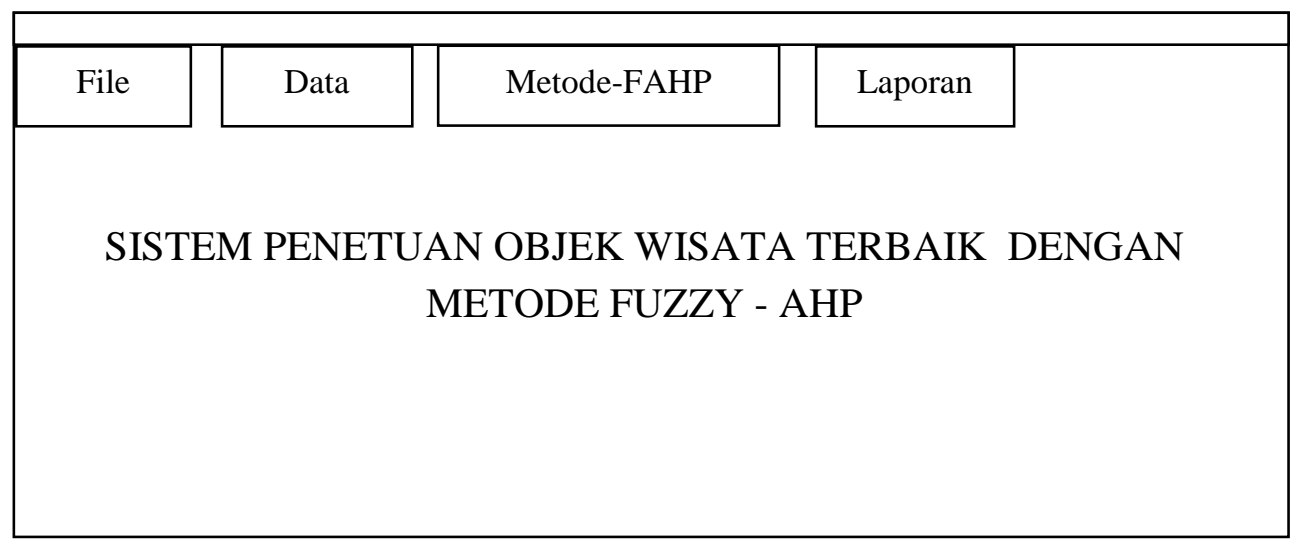

Gambar 14. Rancangan Layar Menu Utama 


\section{KESIMPULAN} berikut:

Berdasarkan hasil perancangan dan analisa maka dapat diambil beberapa kesimpulan sebagai

a. Proses pembobotan kriteria atau sub kriteria dengan metode FAHP bisa diterapkan kedalam bahasa java.

b. Rancangan Penetuan objek wisata terbaik dengan metode FAHP bersifat user freindly.

\section{UCAPAN TERIMA KASIH}

Terima kasih kami ucapkan. Penelitian ini bisa terlaksana atas bantuan dana penelitian dari DPRM DIKTI melalui Kopertis III Jakarta dan Universitas Indraprasta PGRI Jakarta.

\section{DAFTAR PUSTAKA}

[1] Anshori, Y., 2012. Pendekatan Triangular Fuzzy Number dalam Metode Analytic Hierarchy Process. Jurnal Ilmiah Foristek, Volume 2, No. 1.

[2] Bire, C. E. B., Ernawati \& Dwiandiyanta, B. Y., 2012. Perancangan SIstem Pendukung Keputusan Untuk Kenaikan Jabatan Pegawai Menggunakan Fuzzy Analytic Hierarchy Process. Semarang, Seminar Nasional Ilmu Komputer, Universitas Diponegoro.

[3] Kabir, G \& Hasin, A.2011. Comparative Analysis of AHP dan Fuzzy AHP Model For Multi Criteria Inventory Classification. International Journal of Fuzzy Logistic System(IJFLS), Volume 1,No.1.

[4] Saaty, T. L. 2011. Fundamentals of Decision Making and Priority Theory With The Analytic Hierarchy Process. Vol IV. Universitas Pittsburgh. USA.

[5] Shega, H. N. H., Rahmawati, R. \& Yasin, H., 2012. Penentuan Faktor Prioritas Mahasiswa Dalam Memilih Telepon Seluler Merk Blackberry Dengan Fuzzy AHP. Semarang, Seminar Nasional Ilmu Komputer, Universitas Diponegoro.

[6] Syamsiah. Fuzzy Madani. 2016;2(2). Available from: http://journal.lppmunindra.ac.id/index.php/RDJE/article/view/1429/1165

[7] Undang-undang RI No. 9 tahun 1990 tentang kepariwisataan.

[8] Undang-undang Nomor 10 tahun 2009 tentang daya tarik wisata 